\title{
Obstructive sleep apnea and bone mineral density in obese patients
}

This article was published in the following Dove Press journal:

Diabetes, Metabolic Syndrome and Obesity:Targets and Therapy

6 November 2012

Number of times this article has been viewed

\author{
Stefania Mariani' \\ Daniela Fiore' \\ Laura Varone ${ }^{2}$ \\ Sabrina Basciani' \\ Agnese Persichetti' \\ Mikiko Watanabe' \\ Maurizio Saponara ${ }^{3}$ \\ Giovanni Spera' \\ Costanzo Moretti ${ }^{4}$ \\ Lucio Gnessi \\ 'Department of Experimental \\ Medicine, Section of Medical \\ Physiopathology and Endocrinology, \\ Sapienza University of Rome, Italy; \\ ${ }^{2}$ Department of Environmental \\ Biology, Sapienza University of Rome, \\ Italy; ${ }^{3}$ Department of Otolaryngology, \\ Audiology and Phonation, Sapienza \\ University of Rome, Italy; ${ }^{4}$ Division of \\ Endocrinology, Department of System \\ Medicine, Section of Reproductive \\ Endocrinology University \\ of TorVergata, Fatebenefratelli \\ Hospital "San Giovanni Calibita" \\ Rome, Italy
}

Correspondence: Lucio Gnessi Department of Experimental Medicine, Sapienza University of Rome, 0016I-Rome, Italy

Tel +39649970509

Fax +396446I450

Email lucio.gnessi@uniromal.it
Context: Obesity and its co-morbidities may adversely affect bone mineral density (BMD). Obstructive sleep apnea (OSA) is a major complication of obesity. To date, the effects of OSA on BMD in obese patients have been poorly studied.

Objective: To examine whether the severity of OSA independently correlates with BMD in obese patients.

Methods: One hundred and fifteen obese subjects with OSA (Apnea/Hypopnea Index $[\mathrm{AHI}] \geq 5$ events per hour) were included in the study. BMD was measured at lumbar spine, total hip, and femoral neck by dual energy X-ray absorptiometry. Body mass index, lean mass, and representative measures of metabolic syndrome (waist circumference, fasting plasma glucose, blood pressure, HDL-cholesterol, triglycerides) and inflammation (ESR, CRP, fibrinogen) were also evaluated.

Results: BMD did not differ among obese individuals regardless of OSA severity. Correlation coefficient analysis for all the covariates showed a lack of association between AHI and BMD that was strongly influenced by age and weight.

Conclusion: Our study does not support an independent association between AHI and BMD in obese patients. Controlled studies involving a greater number of patients are warranted.

Keywords: obesity, polysomnography, metabolic syndrome

\section{Introduction}

Obstructive sleep apnea (OSA) is a common disorder frequently associated with obesity. ${ }^{1}$ This disorder adversely affects multiple organs and systems ${ }^{2}$ and is characterized by recurrent episodes of partial or complete collapse of the upper airways during sleep, leading to oxygen desaturation and sleep fragmentation. Daytime sleepiness, loud snoring, cardiovascular ${ }^{3,4}$ and metabolic consequences, ${ }^{5}$ and other disorders are eventually associated with OSA. Obesity is a predisposing factor for OSA ${ }^{1,6,7}$ and, in turn, OSA may worsen obesity because of sleep and metabolic derangement. ${ }^{8,9}$ The final effect of OSA's action on bone is unknown. Excess adipose tissue may alter bone mineral density (BMD). Bone is a complex tissue, frequently victim to pathophysiologic mechanisms. Because of BMD reduction, bone is predisposed to osteoporosis, a disease characterized by deterioration of microarchitectural integrity of the bone and increased risk of fracture. Obesity and osteoporosis are reciprocally related. Obesity affects bone metabolism through weight loading and production of cytokines and hormones. Conversely, bone-derived factors influence body weight and adipose tissue. ${ }^{10} \mathrm{~A}$ common mesenchymal stem cell 
progenitor derivation of adipocytes and osteoblasts further confirms the relationship between bone and fat. ${ }^{11}$

Mechanical loading conferred by body weight is traditionally viewed as beneficial to bone health, despite being a risk factor for many other chronic disorders. However, there is no clear consensus regarding the real effect of obesity on $\mathrm{BMD}^{12,13}$ and body mass index (BMI), a non-specific index of obesity, which is often the only measure of body habitus used to evaluate the relationship between obesity and BMD. Recent data strongly support that fat accumulation is detrimental to bone mass. ${ }^{11-13}$ The underlying pathophysiological relationship between obesity and bone is complex and represents an active research area. Obesity-related comorbidities could explain some of the supposed negative effects of excessive fat accumulation on bone.

While obesity-related comorbidities like low grade systemic inflammation, ${ }^{14,15}$ metabolic syndrome, ${ }^{16}$ insulin resistance, diabetes, ${ }^{17}$ and oxidative stress ${ }^{18,19}$ are recognized modifiers of bone metabolism, few studies have evaluated the relationship between OSA and BMD, and it has not been proven that there is one. The relationship between OSA, a potential risk factor for bone mass loss through hypoxia and inflammatory oxidative stress, ${ }^{18,19}$ and bone is poorly studied. In vitro studies have shown that hypoxia induces osteoclast differentiation and bone resorption. ${ }^{20}$ Hypoxia in rats suppresses the functions of osteoblasts by inhibiting their growth, differentiation, and bone-forming capacity. ${ }^{21}$ A report based on a human study provided the evidence of an elevation of the urinary bone resorption marker C-terminal cross-linking telopeptide of type I collagen (CTX) in 50 male OSA patients, suggesting a positive association between OSA and the excretion of CTX, independent of age or BMI. ${ }^{22}$ Furthermore, the authors observed a significant decrease of the urinary excretion of CTX following 3 months' of continuous positive airway pressure. Although these findings suggest a bone mass reduction in subjects suffering from OSA, a clinical limit of the study is the lack of BMD assessment. A significant difference between 21 male OSA patients and a control group in relation to lumbar BMD has been recently reported. ${ }^{23}$ However, the small number and the non-homogeneous weight range of the patients are weak points in the study. Thus, since the balance between osteoclast and osteoblast is disrupted in favor of osteoclast in cases of hypoxia, ${ }^{24-27}$ OSA may be a risk factor for reduced bone mass. $^{28}$

Here, in a cohort of obese patients, we assessed whether OSA associates with changes of BMD after adjustments for relevant covariates such as age, sex, weight, lean mass, and metabolic and inflammatory indices.

\section{Patients and methods}

\section{Study population}

The study population was recruited from the Department of Otolaryngology, Audiology and Phonation, Sapienza University of Rome from June 2010 to June 2011. Inclusion criteria were as follows: BMI $30-40 \mathrm{~kg} / \mathrm{m}^{2}$, age 30-65 years, apnea/hypopnea index (AHI) $\geq 5$ events per hour (events/h). Patients were excluded from the study if affected by hypothyroidism, acromegaly, acute illness, cardiovascular disease, heart failure, lung disease, any other respiratory disorder, uncontrolled hypertension, craniofacial abnormalities, smoking attitude, or if they were using continuous positive airway pressure. Further exclusion criteria were diseases that affect bone metabolism, such as hyperthyroidism, primary hyperparathyroidism, Cushing syndrome, hypogonadism, chronic renal disease, and malignancy. Patients on glucocorticoid, calcium, vitamin $\mathrm{D}$, parathormone, calcitonin, bisphosphonates, strontium ranelate, hypnotics, proton pump inhibitors, and hormone replacement therapy were also excluded. A total of 209 patients were screened and 115 patients (56 male and 59 female) were enrolled in the study. Participants were stratified into three groups according to their AHI: mild OSA (AHI 5-14 events/h), moderate OSA (AHI 15-29 events/h), and severe OSA (AHI $\geq 30$ events/h). Weight and height were measured to the nearest $0.1 \mathrm{~kg}$ and $0.1 \mathrm{~cm}$, respectively. Body mass index was expressed as weight (kilograms)/ height $\left(\right.$ meters $^{2}$ ). Waist circumference (WC) was measured just above the bony landmark of the iliac crest after gentle expiration, and expressed in centimeters. Blood pressure (BP) was measured in the morning, after an overnight fast, by a mercury sphygmomanometer (Riva-Rocci System, ERKA, Chemnitz, Germany). The definition of metabolic syndrome was based on the published third report of the National Cholesterol Education Program's Adult Treatment Panel (ATPIII) criteria. Dyslipidemia was defined as serum triglycerides $\geq 150 \mathrm{mg} / \mathrm{dL}$ and/or high density lipoprotein-cholesterol (HDL-C) $\leq 40 \mathrm{mg} / \mathrm{dL}$ in men and $\leq 50 \mathrm{mg} / \mathrm{dL}$ in women; hypertension as either systolic $\mathrm{BP} \geq 130 \mathrm{mmHg}$ and/or diastolic $\mathrm{BP} \geq 85 \mathrm{mmHg}$; and hyperglycemia as fasting plasma glucose (FPG) $\geq 110 \mathrm{mg} /$ dL. Patients with a previous diagnosis of diabetes mellitus, dyslipidemia, or hypertension were treated with metformin as a glucose-lowering drug, fenofibrate as lipid-lowering treatment, and ace inhibitors or sartans as BP-lowering 
agents. All subjects were enrolled after written consent and approval by the local institution ethics committee.

\section{Assays}

Blood samples were obtained in the morning (between 08:00 and 09:00) by venipuncture after an 8-hour fast. The following measurements were performed: HDL-C, triglycerides (Dimension Dade Behring Analyzer and reagent cartridges from Dade Behring SpA Milano, Italy), plasma glucose (hexokinase method, Aeroset Abbott, Abbott Park, IL, USA), erythrocyte sedimentation rate (ESR; Westergreen method), C-reactive protein (CRP; latex immunoturbidimetric assay; Architech C 8000; Abbott Diagnostics and Laboratories, Abbott Park, IL, USA), and fibrinogen (Clauss method, BCT Dade Behring).

\section{Bone and lean mass evaluation}

BMD and lean mass were measured by Dual Energy X-ray Absorptiometry (DXA) using a DXA scan (Hologic Inc, Bedford, MA, USA, QDR 4500W, S/N 47168) by a single experienced technician, according to the manufacturer's instructions, with the subjects in supine position. Specific delimiters for regional analysis were determined by standard software (Hologic Inc, QDR 4500W S/N 47168 VER. 11.2). Before each scanning session, the densitometer was calibrated according to standard procedures. BMD was assessed at the lumbar spine (L1-L4), at the total hip, and at the femoral neck, and expressed in $\mathrm{g} / \mathrm{cm}^{2}$. At each site, patients with a T score $\geq-1$ were included in the normal group, patients with a T score between $<-1$ and -2.5 were included in the osteopenia group, and patients with a $\mathrm{T}$ score $<-2.5$ were included in the osteoporosis group, as defined by the World Health Organization. ${ }^{29}$ Total lean body mass was expressed both in $\mathrm{kg}$ and percentage.

\section{Polysomnography}

Polysomnography was performed overnight, between 10:00 pm and 6:00 am (Somnoscreen ${ }^{\mathrm{TM}}$ PSG, Somnomedics GmbH Nonnengarten, 8 D-97270 Kist, Germany). Recordings included electroencephalogram, electrooculogram, electromyogram, electrocardiogram, thermistors for nasal and oral airflow, thoracic and abdominal impedance belts for respiratory effort, pulse oximetry for oxyhemoglobin level, a tracheal microphone for snoring, and sensors to assess position changes during sleep. Polysomnography records were scored according to standard criteria. ${ }^{30}$ The degree of OSA was determined by AHI, defined as the total number of obstructive apneas (cessation of airflow for at least 10 seconds) and hypopneas (decrease of the airflow signal amplitude by at least $50 \%$ associated with oxyhemoglobin desaturation by at least $4 \%$ or by arousal) per hour of sleep.

\section{Statistical analysis}

All of the statistical analyses were performed using STATISTICA software version 6.1 (Stat Soft, Inc, Tulsa, Oklahoma). Values were reported as medians with interquartile ranges (25th-75th percentiles), and because of asymmetry in the distribution of some parameters, they were compared using the Kruskal-Wallis one-way analysis of variance test for non-parametric continuous variables and Dunn's multiplecomparison test. Spearman's correlation analyses were conducted to examine linear associations between variables. Differences were considered statistically significant when $P<0.05$.

\section{Results}

The demographic, polysomnographic, anthropometric, metabolic, inflammatory, and BMD characteristics of the patients are shown in Table 1. The patients were stratified into three groups according to their AHI. There were no statistical differences in age, height, weight, BP, and BMI between groups. Except for the HDL-C values, significantly lower in the group with severe OSA, no significant differences in metabolic syndrome parameters were observed. Fibrinogen was significantly higher in the severe OSA group than in the moderate and mild OSA groups; CRP values were significantly lower in the moderate OSA group compared with both the mild and severe OSA groups; serum ESR levels were not statistically different between groups.

Among the 115 patients, 55.65\% had normal BMD $(n=64), 40 \%$ had osteopenia $(n=46)$, and $4.35 \%$ had osteoporosis $(n=5)$. In the group with mild OSA, 15/50 patients were osteopenic $(30 \%)$ and $3 / 50$ patients were osteoporotic (6\%); in the group with moderate OSA, 17/33 patients were osteopenic $(51.52 \%)$ and $0 / 33$ patients were osteoporotic ( $0 \%)$; in the group with severe OSA, 14/32 patients were osteopenic $(43.75 \%)$ and $2 / 32$ patients were osteoporotic $(6.25 \%)$. The BMD values measured at the lumbar spine, total hip, and femoral neck levels were not significantly different among groups. There were no statistically different BMD values between men and women (data not shown).

The sub-cohort of menopausal women (32 patients) showed a lower BMD than the pre-menopausal women (27 patients) at all sites analyzed [L2-L4 BMD, 0.971 (0.89-1.07) g/ $\mathrm{cm}^{2}$ vs 1.09 (1.05-1.11) g/ $\mathrm{cm}^{2}, P<0.05$; hip BMD, 0.956 (0.85-1.08) g/cm² vs 1.03 (0.95-1.1) g/cm², 
Table I Descriptive characteristics of subjects with varying severities of obstructive sleep apnea (OSA)

\begin{tabular}{|c|c|c|c|c|}
\hline & Total & $\begin{array}{l}\text { Mild OSA } \\
\text { (AHI 5-I4/h) }\end{array}$ & $\begin{array}{l}\text { Moderate OSA } \\
\text { (AHI I5-29/h) }\end{array}$ & $\begin{array}{l}\text { Severe OSA } \\
(A H I \geq 30 / h)\end{array}$ \\
\hline Number & 115 & 50 & 33 & 32 \\
\hline Male/female & $56 / 59$ & $16 / 34$ & $19 / 14$ & $21 / 11$ \\
\hline Age $(y r)$ & $\begin{array}{l}56.00 \\
(47.25-61.75)\end{array}$ & $\begin{array}{l}55.00 \\
(44.5-58.75)\end{array}$ & $\begin{array}{l}56.00 \\
(49.75-62.0)\end{array}$ & $\begin{array}{l}57.00 \\
(50.0-63.0)\end{array}$ \\
\hline AHI (events/h) & $\begin{array}{l}17.00 \\
(8.5-30.75)\end{array}$ & $\begin{array}{l}8.0 \\
(6.0-10.12)\end{array}$ & $\begin{array}{l}22.5 \\
(17.4-25.9)^{\mathrm{a}}\end{array}$ & $\begin{array}{l}45.9 \\
(39.7-63.92)^{\mathrm{a}, \mathrm{b}}\end{array}$ \\
\hline Height (cm) & $\begin{array}{l}168.0 \\
(161.0-173.0)\end{array}$ & $\begin{array}{l}167.5 \\
(|58.0-| 7 \mid .2)\end{array}$ & $\begin{array}{l}168.0 \\
(161.0-174.5)\end{array}$ & $\begin{array}{l}168.0 \\
(165.0-174.0)\end{array}$ \\
\hline Body weight (kg) & $\begin{array}{l}101.1 \\
(90.0-111.9)\end{array}$ & $\begin{array}{l}97.25 \\
(87.75-112.8)\end{array}$ & $\begin{array}{l}100.0 \\
(89.5-109.8)\end{array}$ & $\begin{array}{l}104.5 \\
(97.25-119.25)\end{array}$ \\
\hline BMI $\left(\mathrm{kg} / \mathrm{m}^{2}\right)$ & $\begin{array}{l}35.41 \\
(32.16-39.72)\end{array}$ & $\begin{array}{l}36.10 \\
(31.67-40.55)\end{array}$ & $\begin{array}{l}34.78 \\
(31.75-38.07)\end{array}$ & $\begin{array}{l}36.86 \\
(33.44-49.9)\end{array}$ \\
\hline Lean mass $(\mathrm{kg})$ & $\begin{array}{l}57.7 \\
(51.31-65.53)\end{array}$ & $\begin{array}{l}54.8 \\
(48.82-59.48)\end{array}$ & $\begin{array}{l}59.23 \\
(51.77-67.82)\end{array}$ & $\begin{array}{l}64.52 \\
(55.69-69.54)^{\mathrm{a}}\end{array}$ \\
\hline \multicolumn{5}{|c|}{ Metabolic syndrome Indicators } \\
\hline WC $(\mathrm{cm})$ & $\begin{array}{l}106.5 \\
(101.3-123.0)\end{array}$ & $\begin{array}{l}106.7 \\
(99.5-117.25)\end{array}$ & $\begin{array}{l}104.3 \\
(101.2-119.0)\end{array}$ & $\begin{array}{l}108.7 \\
(102.9-128.5)\end{array}$ \\
\hline FPG (mg/dL) & $\begin{array}{l}98.0 \\
(90.0-105.0)\end{array}$ & $\begin{array}{l}96.5 \\
(89.0-102.2)\end{array}$ & $\begin{array}{l}98.0 \\
(91.0-108.5)\end{array}$ & $\begin{array}{l}100.0 \\
(89.25-1 \mid 2.2)\end{array}$ \\
\hline Systolic BP (mmHg) & $\begin{array}{l}140.0 \\
(130.0-145.0)\end{array}$ & $\begin{array}{l}132.5 \\
(120.0-140.5)\end{array}$ & $\begin{array}{l}140.0 \\
(129.0-143.5)\end{array}$ & $\begin{array}{l}140.0 \\
(130.0-150.0)\end{array}$ \\
\hline Diastolic BP (mmHg) & $\begin{array}{l}90.0 \\
(80.0-90.0)\end{array}$ & $\begin{array}{l}85.5 \\
(80.0-90.0)\end{array}$ & $\begin{array}{l}90.0 \\
(80.0-90.0)\end{array}$ & $\begin{array}{l}90.0 \\
(81.25-95.0)\end{array}$ \\
\hline $\mathrm{HDL}-\mathrm{C}(\mathrm{mg} / 100 \mathrm{~mL})$ & $\begin{array}{l}44.3 \\
(37.77-52.0)\end{array}$ & $\begin{array}{l}49.0 \\
(41.75-55.1)\end{array}$ & $\begin{array}{l}43.00 \\
(36.0-51.0)\end{array}$ & $\begin{array}{l}39.15 \\
(35.0-49.25)^{\mathrm{a}}\end{array}$ \\
\hline Triglycerides (mg/dL) & $\begin{array}{l}140.0 \\
(110.25-168.75)\end{array}$ & $\begin{array}{l}138.6 \\
(107.8-167.2)\end{array}$ & $\begin{array}{l}130.0 \\
(107.5-175.0)\end{array}$ & $\begin{array}{l}151.5 \\
(117.5-174.0)\end{array}$ \\
\hline \multicolumn{5}{|l|}{ Inflammatory indicators } \\
\hline $\operatorname{ESR}(\mathrm{mm} / \mathrm{h})$ & $\begin{array}{l}22.0 \\
(13.25-29.0)\end{array}$ & $\begin{array}{l}18.5 \\
(11.5-30.5)\end{array}$ & $\begin{array}{l}18.0 \\
(14.5-27.0)\end{array}$ & $\begin{array}{l}26.0 \\
(22.0-29.75)\end{array}$ \\
\hline CRP (mg/dL) & $\begin{array}{l}0.8 \\
(0.6-1.1)\end{array}$ & $\begin{array}{l}0.97 \\
(0.57-1.39)\end{array}$ & $\begin{array}{l}0.7 \\
(0.5-0.85)^{\mathrm{a}}\end{array}$ & $\begin{array}{l}0.9 \\
(0.8-0.99)\end{array}$ \\
\hline Fibrinogen (mg/dL) & $\begin{array}{l}378.0 \\
(350.2-4 \mid 5.75)\end{array}$ & $\begin{array}{l}370.0 \\
(329.7-4 \mid 3.2)\end{array}$ & $\begin{array}{l}360.0 \\
(335.0-375.0)\end{array}$ & $\begin{array}{l}404.0 \\
(390.0-424.2)^{\mathrm{a}, \mathrm{b}}\end{array}$ \\
\hline \multicolumn{5}{|l|}{ BMD indicators } \\
\hline $\mathrm{LI}-\mathrm{L} 4\left(\mathrm{~g} / \mathrm{cm}^{2}\right)$ & $\begin{array}{l}1.05 \\
(0.94-1.11)\end{array}$ & $\begin{array}{l}1.05 \\
(0.93-1.12)\end{array}$ & $\begin{array}{l}1.01 \\
(0.89-1.08)\end{array}$ & $\begin{array}{l}1.06 \\
(1.04-1.14)\end{array}$ \\
\hline Total hip $\left(\mathrm{g} / \mathrm{cm}^{2}\right)$ & $\begin{array}{l}1.02 \\
(0.93-1.11)\end{array}$ & $\begin{array}{l}1.01 \\
(0.93-1.11)\end{array}$ & $\begin{array}{l}0.99 \\
(0.92-1.05)\end{array}$ & $\begin{array}{l}1.05 \\
(0.96-1.15)\end{array}$ \\
\hline Femoral neck $\left(\mathrm{g} / \mathrm{cm}^{2}\right)$ & $\begin{array}{l}0.83 \\
(0.75-0.96)\end{array}$ & $\begin{array}{l}0.88 \\
(0.74-0.97)\end{array}$ & $\begin{array}{l}0.79 \\
(0.74-0.91)\end{array}$ & $\begin{array}{l}0.79 \\
(0.77-0.96)\end{array}$ \\
\hline Osteopenia, $\mathrm{n}^{\circ}$ and $(\%)$ & $46(44.35 \%)$ & $15(30 \%)$ & $17(51.52 \%)$ & 14 (43.75\%) \\
\hline Osteoporosis, $\mathrm{n}^{\circ}$ and (\%) & $5(\%)$ & $3(6 \%)$ & $0(0 \%)$ & $2(6.25 \%)$ \\
\hline \multicolumn{5}{|c|}{ BMD of women in pre-menopause and menopause } \\
\hline \multicolumn{5}{|l|}{ Menopause } \\
\hline L2-L4 BMD $\left(\mathrm{g} / \mathrm{cm}^{2}\right)$ & $\begin{array}{l}0.971 \\
(0.89-1.07)\end{array}$ & $\begin{array}{l}0.97 \\
(0.8 I-1.2)\end{array}$ & $\begin{array}{l}0.92 \\
(0.86-1.0)\end{array}$ & $\begin{array}{l}1.05 \\
(0.84-1.11)\end{array}$ \\
\hline Hip BMD $\left(\mathrm{g} / \mathrm{cm}^{2}\right)$ & $\begin{array}{l}0.956 \\
(0.859-1.082)\end{array}$ & $\begin{array}{l}0.98 \\
(0.83-1.09)\end{array}$ & $\begin{array}{l}0.93 \\
(0.86-0.96)\end{array}$ & $\begin{array}{l}\text { I.I } \\
(0.92-1.15)\end{array}$ \\
\hline Femoral neck BMD $\left(\mathrm{g} / \mathrm{cm}^{2}\right)$ & $\begin{array}{l}0.77 \\
(0.639-0.907)\end{array}$ & $\begin{array}{l}0.82 \\
(0.63-0.94)\end{array}$ & $\begin{array}{l}0.69 \\
(0.64-0.77)\end{array}$ & $\begin{array}{l}0.88 \\
(0.7 I-I . I)\end{array}$ \\
\hline \multicolumn{5}{|l|}{ Pre-menopause } \\
\hline L2-L4 BMD (g/cm²) & $\begin{array}{l}1.09 \\
(1.05-1.11)\end{array}$ & $\begin{array}{l}1.1 \\
(1.04-1.12)\end{array}$ & $\begin{array}{l}1.08 \\
(0.96-1.3)\end{array}$ & $\begin{array}{l}1.06 \\
(0.98-1.09)\end{array}$ \\
\hline Hip BMD $\left(\mathrm{g} / \mathrm{cm}^{2}\right)$ & $\begin{array}{l}1.031 \\
(0.95-1.10)\end{array}$ & $\begin{array}{l}1.02 \\
(0.99-1.1)\end{array}$ & $\begin{array}{l}1.03 \\
(0.92-1.26)\end{array}$ & $\begin{array}{l}1.06 \\
(0.86-1.12)\end{array}$ \\
\hline
\end{tabular}


Table I (Continued)

\begin{tabular}{lllll}
\hline & Total & $\begin{array}{l}\text { Mild OSA } \\
\text { (AHI 5-14/h) }\end{array}$ & $\begin{array}{l}\text { Moderate OSA } \\
(\text { AHI I5-29/h) }\end{array}$ & $\begin{array}{l}\text { Severe OSA } \\
(\mathbf{A H I} \geq \mathbf{3 0 / h})\end{array}$ \\
\hline Femoral neck BMD $\left(\mathrm{g} / \mathrm{cm}^{2}\right)$ & 0.88 & 0.90 & 0.92 & 0.80 \\
& $(0.80-0.95)$ & $(0.81-0.95)$ & $(0.83-1.1)$ & $(0.72-0.85)$ \\
\hline
\end{tabular}

Notes: Values are expressed as median values, 25 th-75th percentiles; ${ }^{a}$ significantly different from mild OSA group $(P<0.05)$; ${ }^{b}$ significantly different from moderate OSA group $(P<0.05)$.

Abbreviations: AHI, apnea-hypopnea index; BMI, body mass index; WC, waist circumference; FPG, fasting plasma glucose; BP, blood pressure; HDL-C, high density lipoprotein-cholesterol; MetS, metabolic syndrome; ESR, erythrocyte sedimentation rate; CRP, C-reactive protein; BMD, bone mineral density; OSA, obstructive sleep apnea.

$P<0.05$; femoral neck BMD, $0.77(0.639-0.907) \mathrm{g} / \mathrm{cm}^{2}$ vs $\left.0.88(0.8-0.95) \mathrm{g} / \mathrm{cm}^{2}, P<0.05\right]$.

However, independent from the menopause status, no significant differences in BMD were found when the patients were distributed in the mild, moderate, and severe OSA groups, given that the increasing severity of OSA was not accompanied by a reduction in BMD (Table 1).

Lean body mass was significantly higher in men than in women, both in $\mathrm{kg}$ [men 65.23 (59.38-70.29) vs women 51.52 (48.19-56.53); $P<0.001$ ] and in percentage [men 63.48 (57.56-68.38) vs women 54.06 (49.66-58.56); $P<0.001]$. Moreover, we observed a higher lean mass in severe OSA groups compared to the group with mild OSA (Table 1).

Table 2 shows a linear correlation between the variables. Spearman's coefficients showed a lack of association between AHI and BMI, body weight, WC, FPG, CRP, triglycerides, and BMD at all bone sites. Indeed, lumbar spine, total hip, and femoral neck BMD were positively correlated to weight $(P \leq 0.001)$ and inversely correlated to age $(P \leq 0.001)$. Moreover, there was a correlation between total hip and lumbar BMD and lean mass, but not between femoral neck $\mathrm{BMD}$ and lean mass.

A significant association of AHI with ESR and fibrinogen was found; ESR correlated with weight, BMI, WC, diastolic blood pressure, and CRP; while fibrinogen associated with weight, WC, CRP, and ESR. CRP did not associate with any of the covariates except BMI. Finally, the lean mass showed a significant positive correlation with AHI, weight, WC, and fibrinogen, and a negative correlation with HDL-C and age.

\section{Discussion}

We explored the correlation between AHI and BMD in obese men and women with OSA. Our data indicate that, in obese patients, there is no relationship between OSA and BMD was strongly affected by age but not by OSA. After stratification of women on the basis of OSA severity, AHI was not relevant to bone loss regardless of menopause status. On the whole, these results suggest that OSA does not lead to a severityrelated reduction of BMD in obese patients.

Table 2 Spearman's correlation coefficient analysis for all the covariates

\begin{tabular}{|c|c|c|c|c|c|c|c|c|c|c|c|c|c|c|}
\hline & AHI & Age & Weight & BMI & WC & FPG & SBP & DBP & HDL-C & TG & CRP & ESR & Fibrinogen & Lean mass \\
\hline $\mathrm{AHI}$ & & & & & & & & & & & & & & $0.32^{\ddagger}$ \\
\hline Age & $0.2^{\dagger}$ & & & & & & & & & & & & & $-0.19^{\dagger}$ \\
\hline Weight & 0.10 & $-0.40^{\ddagger}$ & & & & & & & & & & & & $0.58^{\ddagger}$ \\
\hline BMI & -0.01 & $-0.23^{\dagger}$ & $0.72^{\ddagger}$ & & & & & & & & & & & 0.16 \\
\hline WC & 0.09 & $-0.24^{\dagger}$ & $0.73^{\ddagger}$ & $0.73^{\ddagger}$ & & & & & & & & & & $0.32^{\ddagger}$ \\
\hline FPG & 0.11 & $0.21 \dagger$ & $0.22^{\dagger}$ & $0.22^{\dagger}$ & $0.21^{\dagger}$ & & & & & & & & & 0.05 \\
\hline Systolic BP & $0.19^{\dagger}$ & $0.34^{\ddagger}$ & 0.00 & 0.02 & 0.13 & $0.25^{\dagger}$ & & & & & & & & 0.07 \\
\hline Diastolic BP & $0.21^{\dagger}$ & $0.30^{\ddagger}$ & -0.03 & -0.02 & 0.09 & 0.07 & $0.78^{\ddagger}$ & & & & & & & 0.03 \\
\hline HDL-C & $-0.23^{\dagger}$ & -0.08 & -0.14 & 0.05 & -0.00 & -0.03 & $-0.26^{\dagger}$ & $-0.19^{\dagger}$ & & & & & & $-0.35^{\ddagger}$ \\
\hline TG & 0.02 & $0.20^{\dagger}$ & 0.01 & 0.08 & 0.05 & $0.25^{\dagger}$ & $0.26^{\dagger}$ & 0.16 & $-0.24^{\dagger}$ & & & & & 0.09 \\
\hline CRP & -0.01 & 0.05 & 0.12 & $0.18^{\dagger}$ & 0.16 & 0.06 & 0.03 & -0.01 & -0.07 & 0.14 & & & & 0.03 \\
\hline ESR & $0.19^{\dagger}$ & -0.05 & $0.28^{\dagger}$ & $0.29^{\dagger}$ & $0.35^{\ddagger}$ & 0.12 & 0.12 & $0.19^{\dagger}$ & -0.18 & 0.15 & $0.43^{\ddagger}$ & & & 0.16 \\
\hline Fibrinogen & $0.27^{\dagger}$ & -0.07 & $0.20^{\dagger}$ & 0.16 & $0.19^{\dagger}$ & 0.02 & 0.04 & 0.11 & -0.17 & 0.03 & $0.50^{\ddagger}$ & $0.48^{\ddagger}$ & & $0.20^{\dagger}$ \\
\hline LI-L4 BMD & 0.00 & $-0.3 I^{\ddagger}$ & $0.34^{\ddagger}$ & $0.28^{\dagger}$ & 0.14 & -0.04 & $-0.20^{\dagger}$ & $-0.20^{\dagger}$ & -0.02 & -0.08 & -0.04 & 0.13 & 0.11 & $0.18^{\dagger}$ \\
\hline Hip BMD & 0.06 & $-0.30^{\ddagger}$ & $0.32^{\ddagger}$ & 0.17 & $0.24^{\dagger}$ & 0.03 & 0.03 & -0.02 & -0.18 & -0.04 & -0.02 & 0.17 & 0.16 & $0.24^{\dagger}$ \\
\hline FN BMD & -0.11 & $-0.35^{\ddagger}$ & $0.28^{\dagger}$ & 0.18 & 0.15 & -0.01 & -0.04 & -0.12 & -0.07 & -0.10 & 0.05 & 0.14 & 0.08 & 0.16 \\
\hline
\end{tabular}

Notes: ${ }^{\dagger} P<0.05 ; \ddagger P<0.001$.

Abbreviations: AHI, apnea-hypopnea index; BMI, body mass index; WC, waist circumference; FPG, fasting plasma glucose; DBP, diastolic blood pressure; HDL-C, high density lipoprotein-cholesterol; TG, triglycerides; CRP, C-reactive protein; ESR, erythrocyte sedimentation rate; FN, femoral neck; BMD, bone mineral density; SBP, systolic blood pressure. 
According to previous studies, ${ }^{31,32}$ we found that weight is an independent contributor to BMD; conversely, BMI, a surrogate index of obesity, was not a good predictor for BMD. A possible explanation for this discrepancy may reside in the complexity of body composition. Several authors examined the relationships between fat or lean mass and BMD. ${ }^{33,34}$ In particular, a consistent positive relationship between lean mass and BMD has been reported. ${ }^{33-35} \mathrm{We}$ found a positive correlation between lean mass and BMD at hip level and in the lumbar spine. The lean mass-hip BMD association was not unexpected since a recent study showed a strong relationship between lean mass, hip geometry, and BMD. $^{36}$ Interestingly, we observed higher lean mass values in moderate and severe OSA groups and a correlation between lean mass and AHI. A previous study to determine the predictive value of regional fat distribution for OSA severity showed an association of lean mass of the trunk and AHI. ${ }^{37}$ It is currently unknown whether this association has a pathophysiological meaning. However, these findings suggest that DEXA-quantified fat and lean mass distribution in different body regions might be more informative than anthropometric measurements, such as WC or BMI, in examining potential causal relationships and predictive values between body composition and OSA severity.

Our data confirm the relationship between OSA and chronic inflammation. However, despite a pro-inflammatory state frequently representing the common denominator of OSA $^{14,18,21}$ and osteopenia and osteoporosis, ${ }^{38}$ we did not find a correlation between inflammatory indices and BMD. This finding is difficult to explain. There are various molecular mediators between inflammation and bone. A possible relationship between inflammatory markers different from the markers measured here, such as pro-inflammatory cytokines and BMD, cannot be completely ruled out.

Some intrinsic limitations of the present study must be highlighted. We did not measure the vitamin D concentration in our patients. The implications of vitamin $\mathrm{D}$ in bone metabolism are well known, and in obesity, a vitamin D deficit could be associated with an increased degree of inflammation..$^{39}$ Nonetheless, a lack of association between vitamin D and BMD has been reported. ${ }^{40}$ Although ESR, $\mathrm{CRP}$, and fibrinogen are major and reliable indices of inflammatory status in clinical practice, TNF-alfa, ${ }^{41} \mathrm{IL}-6,{ }^{42}$ and other cytokines involved in bone loss and OSA should be analyzed. Finally, although our aim was to compare groups of patients with various degrees of OSA, the lack of a control population and the relatively small sample size remain weak points.
In conclusion, this cross-sectional study of obese OSA patients shows that $\mathrm{AHI}$ is not associated with bone density independent from weight, lean mass, metabolic syndrome, and inflammation, and OSA is not as important as age, weight, and lean mass on bone. These results are not in line with previous evidence of correlation between AHI and lumbar spine osteoporosis in men. ${ }^{23}$ Therefore, the controversy regarding the effect of obesity on BMD is not explainable by the increased severity of OSA. These preliminary data, taken together, deserve further characterization and focus on larger cohorts of obese OSA patients, particularly in prospective studies. Elucidation of this relationship will generate research interest in the coming years.

\section{Acknowledgment}

This study was funded by the Sapienza University of Rome, Italy. The funding source had no role in study design; collection, analysis, and interpretation of data; or the writing of the report and the decision to submit the paper for publication.

\section{Disclosure}

The authors declare that there is no conflict of interest in this work.

\section{References}

1. Romero-Corral A, Caples SM, Lopez-Jimenez F, Somers VK. Interactions between obesity and obstructive sleep apnea: implication for treatment. Chest. 2010;137(3):711-719.

2. Zamarron C, García Paz V, Riveiro A. Obstructive sleep apnea syndrome is a systemic disease. Current evidence. Eur J Intern Med. 2008;19(6):390-398.

3. Almendros I, Farré R, Torres M, et al. Early and mid-term effects of obstructive apneas in myocardial injury and inflammation. Sleep Med. 2011;12(10):1037-1040.

4. Mariani S, Fiore D, Barbaro G, et al. Association of epicardial fat thickness with the severity of obstructive sleep apnea in obese patients. Int J Cardiol. 2012 Jun 20; [In press].

5. Bonsignore MR, Zito A. Metabolic effects of the obstructive sleep apnea syndrome and cardiovascular risk. Arch Physiol Biochem. 2008;114(4):255-260.

6. Newman AB, Foster G, Givelber R, Nieto FJ, Redine S, Young T. Progression and regression of sleep-disordered breathing with changes in weight: the Sleep Health Study. Arch Intern Med. 2005;165(20): 2408-2413.

7. Foster GD, Sanders MH, Millman R, et al; Sleep AHEAD Research Group. Obstructive sleep apnea among obese patients with type 2 diabetes. Diabetes Care. 2009;32(17):1017-1019.

8. Attal P, Chanson P. Endocrine aspects of obstructive sleep apnea. J Clin Endocrinol Metab. 2010;95(2):483-495.

9. Van Cauter E, Spiegel K, Tasali E, Leproult R. Metabolic consequences of sleep and sleep loss. Sleep Med. 2008;9 Suppl:s23-s28.

10. Gomez-Ambrosi J, Rodríguez A, Catalàn V, Frühbeck G. The boneadipose axis in obesity and weight loss. Obes Surg. 2008;18(9): 1134-1143.

11. Cao JJ. Effects of obesity on bone metabolism. J Orthop Surg Res. $2011 ; 15(6): 30-37$. 
12. Zhao LJ, Liu YJ, Liu PY, Hamilton J, Recker RR, Deng HW. Relationship of obesity with osteoporosis. J Clin Endocrinol Metab. 2007;92(5):1640-1646.

13. Zhao LJ, Jiang H, Papasian CJ, Drees B, Hamilton J, Deng HW. Correlation of obesity and osteoporosis: effect of fat mass on the determination of osteoporosis. J Bone Miner Res. 2008;23(1):17-29.

14. Vgontzas AN. Does obesity play a major role in the pathogenesis of sleep apnoea and its associated manifestations via inflammation, visceral adiposity, and insulin resistance? Arch Physiol Biochem. 2008;114(4):211-223.

15. Ryan S, Taylor CT, McNicholas WT. Systemic inflammation: a key factor in the pathogenesis of cardiovascular complications in obstructive sleep apnoea syndrome? Thorax. 2009;64(7):631-636.

16. von Muhlen D, Safii S, Jassal SK, Svartberg J, Barrett-Connor E. Associations between the metabolic syndrome and bone health in older men and women: the Rancho Bernardo Study. Osteoporos Int. 2007;18(10):1337-1344

17. Pietschmann P, Patsch JM, Schernthaner G. Diabetes and bone. Horm Metab Res. 2010;42(11):763-768.

18. Jelic S, Lederer DJ, Adams T, et al. Vascular inflammation in obesity and sleep apnea. Circulation. 2010;121(8):1014-1021.

19. Lavie L. Oxidative stress inflammation and endothelial dysfunction in obstructive sleep apnea. Front Biosci. 2012;4:1391-1403.

20. Utting JC, Flanagan AM, Brandao-Burch A, Orriss IR, Arnett TR. Hypoxia stimulates osteoclast formation from human peripheral blood. Cell Biochem Funct. 2010;28(5):374-380.

21. Utting JC, Robins SP, Brandao-Burch A, Orriss IR, Behar J, Arnett TR Hypoxia inhibits the growth, differentiation and bone-forming capacity of rat osteoblasts. Exp Cell Res. 2006;312(10):1693-1702.

22. Tomiyama H, Okazaki R, Inoue D, et al. Link between obstructive sleep apnea and increased bone resorption in men. Osteoporos Int. 2008;19(8):1185-1192.

23. Uzkeser H, Yildirim K, Aktan B, et al. Bone mineral density in patients with obstructive sleep apnea syndrome. Sleep Breath. 2012; [Epub ahead of print.]

24. Arnett TR, Gibbons DC, Utting JC, et al. Hypoxia is a major stimulator of osteoclast formation and bone resorption. J Cell Physiol. 2003;196(1):2-8.

25. Arnett TR. Acidosis, hypoxia and bone. Arch Biochem Biophys. 2010;503(1):103-109.

26. Genetos DC, Toupadakis CA, Raheja LF, Wong A, Papanicolaou SE, Fyhrie DP, et al. Hypoxia decreases sclerostin expression and increases Wnt signaling in osteoblasts. J Cell Biochem. 2010;110(2):457-467.

27. Basu S, Michaëlsson K, Olofsson H, Johansson S, Melhus H. Association between oxidative stress and bone mineral density. Biochem Biophys Res Commun. 2001;288(1):275-279.

28. Halpern R, Becker L, Iqbal SU, Kazis LE, Macarios D, Badamgarav E. The association of adherence to osteoporosis therapies with fracture, all-cause medical costs, and all-cause hospitalizations: a retrospective claims analysis of female health plan enrollees with osteoporosis. J Manag Care Pharm. 2011;17(1):25-39.
29. Kanis JA. Assessment of fracture risk and its application to screening for postmenopausal osteoporosis: Synopsis of a WHO report. Osteoporos Int. 1994;4(6):368-381.

30. Iber C, Ancoli-Israel S, Chesson AL, Quan SF Jr. The AASM manual for the scoring of sleep and associated events: rules, terminology and technical specifications. 2007 American Academy of Sleep Medicine, 1 Westbrook Corporate Center, Westchester, IL 60154 USA.

31. Robbins J, Schott AM, Azari R, Kronmal R. Body mass index is not a good predictor of bone density: results from WHI, CHS, and EPIDOS. J Clinical Densitom. 2006;9(3):329-334.

32. Martinez-Rivera C, Abad J, Fiz JA, Rios J, Morera J. Usefulness of truncal obesity indices as predictive factors for obstructive sleep apnea syndrome. Obesity (Silver Spring). 2008;16(1):113-118.

33. Park JH, Song YM, Sung J, et al. The association between fat and lean mass and bone mineral density: the Healthy Twin Study. Bone. 2012;50(4):1006-1011.

34. Cheng Q, Zhu YX, Zhang MX, Li LH, Du PY, Zhu MH. Age and sex effects on the association between body composition and bone mineral density in healthy Chinese men and women. Menopause. 2012;19(4):448-455.

35. Genaro PS, Pereira GA, Pinheiro MM, Szejnfeld VL, Martini LA. Influence of body composition on bone mass in postmenopausal osteoporotic women. Arch Gerontol Geriatr. 2010;51(3):295-298.

36. Hu WW, Zhang H, Wang C, et al. Lean mass predicts hip geometry and bone mineral density in Chinese men and women and age comparisons of body composition. J Clin Densitom. 2012; [Epub ahead of print.]

37. Simpson L, Mukherjee S, Cooper MN, et al. Sex differences in the association of regional fat distribution with the severity of obstructive sleep apnea. Sleep. 2010;33(4):467-474.

38. Liang B, Feng Y. Endocrine. 2011;42(1):190-195.

39. Vilarrasa N, Vendrell J, Maravall J, et al. Is plasma $25(\mathrm{OH}) \mathrm{D}$ related to adipokines, inflammatory cytokines and insulin resistance in both a healthy and morbidly obese population? Endocrine. 2010;38(2): $235-242$.

40. Triantafyllou N, Lambrinoudaki I, Thoda P, et al. Lack of association between vitamin $\mathrm{D}$ levels and bone mineral density in patients with multiple sclerosis. J Neurol Sci. 2012;313(1-2):137-141.

41. Ryan S, Taylor CT, McNicholas WT. Selective activation of inflammatory pathways by intermittent hypoxia in obstructive sleep apnea syndrome. Circulation. 2005;112(17):2660-2667.

42. Sahlman J, Seppä J, Herder C, et al. Effect of weight loss on inflammation in patients with mild obstructive sleep apnea. Nutr Metab Cardiovasc Dis. 2010;22(7):583-590.

Diabetes, Metabolic Syndrome and Obesity: Targets and Therapy

Dovepress

\section{Publish your work in this journal}

Diabetes, Metabolic Syndrome and Obesity: Targets and Therapy is an international, peer-reviewed open-access journal committed to the rapid publication of the latest laboratory and clinical findings in the fields of diabetes, metabolic syndrome and obesity research Original research, review, case reports, hypothesis formation, expert opinion and commentaries are all considered for publication. The manuscript management system is completely online and includes a very quick and fair peer-review system, which is all easy to use. Visit http://www.dovepress.com/testimonials.php to read real quotes from published authors. 